\title{
Effects of Vitamin D and/or Aquatic Exercise on IL-1ß and IL-1RA Serum Levels and Behavior of Children with Autism Spectrum Disorder
}

\author{
Soleyman Ansari', Fahimeh AdibSaber ${ }^{\star}$, Alireza Elmieh ${ }^{r}$
}

Received 05 June 2020, Accepted for publication 04 October 2020

\begin{abstract}
Background \& Aims: Immune system abnormalities such as inflammation, increased autoimmunity and the skewed expression of soluble mediators, including cytokines have been observed in autistic patients. The present study aimed to compare the effects of vitamin D supplementation and/or aquatic exercise training on the serum level of inflammatory cytokines, including IL-1 $\beta$ and IL1RA, and stereotypic behaviors (S.B) of children with autism spectrum disorders (ASD).

Materials \& Methods: We recruited 40 children with ASD (aged 6-14) and divided them into the aquatic exercise $(\mathrm{n}=10)$, vitamin D supplementary $(n=10)$, aquatic +supplementation $(n=10)$, and control $(n=10)$ groups. Participants in the aquatic exercise group performed water-based activities for 10 weeks/2 sessions per week/60 min, while the participants of the supplementary group orally received 50,000 IU vitamin D3/ day, and the combined group received both exercise and supplementation, control group did not get any intervention. We evaluated the participants' serum levels of IL-1 $\beta$, IL-1RA and S.B scores at baseline and the end of the treatment. Results: Results revealed that all three interventional approaches improved behavioral symptoms and IL-1 $\beta$ serum level; interestingly, only the combined intervention could significantly affect IL-1RA.

Conclusions: We concluded that both aqua-based exercise and vitamin D supplements could lead to significant improvement in serum cytokine levels and behavioral problems in children with ASD.
\end{abstract}

Keywords: Autism, IL-1 $\beta$, IL-1RA, Aquatic Exercise, Vitamin D Supplements

Address: Department of Physical Education, College of Humanities, Azad University of Rasht, Lakan Blvd., Rasht, Iran

Tel: +989101033889

Email: adibsaber@iaurasht.ac.ir

\section{Introduction}

Autism spectrum disorder (ASD) is a biologically neurodevelopmental disorder characterized by two main core symptoms, impairments in social and communicational skills and restricted /repetitive behaviors (1). The prevalence of ASD has increased dramatically all over the world, but it is estimated that this rate is 10 per 10,000 for typical autism in Iran, lower than those recited recently for some western nations (2).

\footnotetext{
${ }^{1}$ Ph.D. Exercise Physiology, Department of Physical Education, Rasht Branch, Islamic Azad University, Rasht, Iran

${ }^{2}$ Assistant Professor of Motor Behavior, Department of Physical Education, Rasht Branch, Islamic Azad University, Rasht, Iran (Corresponding Author)

${ }^{3}$ Assistant Professor of Exercise Physiology, Department of Physical Education, Rasht Branch, Islamic Azad University, Rasht, Iran
} 
Although the precise etiology of autism is unknown, current evidence suggests that there is a complex interplay of environmental, genetic, and immunological mechanisms. Some studies investigated the immune function in ASD and found that inflammation could play important roles in the pathogenesis and persistence of complex neurological and behavioral abnormalities associated with $\operatorname{ASD}(1,3)$. Both adaptive and innate immune system abnormalities such as inflammation, immunodeficiency, increased autoimmunity, altered cellular immunity, and skewed expression of soluble mediators, including cytokines are addressed in autistic patients and their family members (mainly mothers) (4, $5)$.

Immune mediators known as cytokines are fundamental facilitators of cross-systemic communication. Cytokines are proteins that manage the nature, duration, and intensity of an immune response. Interestingly, cytokines also may facilitate processes of immune-CNS interactions, which regulate not only inflammatory feedback within the CNS but also neuroimmune mechanisms correlated with neuronal homeostasis, synaptic plasticity, and neural function. Their significance differs according to the timing, duration, and intensity of the neuro-immune interaction (6).

IL-1 beta (IL-1 $\beta$ ), a pro-inflammatory cytokine that is released by macrophages in response to systemic inflammation, belongs to a family of evolving protected proteins. IL-1 $\beta$ participates in neural processes and appears to play a role in both CNS pathology and CNS treatment (7). Genetic mechanisms or environmental impacts may change IL- $1 \beta$ systems and contribute to autism. The normal homeostatic levels of IL-1 $\beta$ and its antagonist IL-1RA are fundamental for appropriate brain function and growth (8). IL-1RA (IL-1 receptor antagonist), mainly produced by monocytes, neutrophils, microglia cells, liver cells, and many other cells in response to tissue damage, infections, and inflammation, reduces inflammation in the rivalry for the IL-1 $\beta$ receptor, and higher levels may be an attempt to cope with inflammation in the ASD (7).

Previous studies that examined serum and plasma levels of specific cytokines in autistic subjects, reported that IL-1 $\beta$ and IL-1RA were significantly higher in ASD populations, compared to healthy controls $(4,7,9)$, proposing that IL-1RA might have arisen as a negative feedback regulator in response to the elevation of IL-1 $\beta$ levels in ASD. In addition, it is reported that increased stereotypy was associated with increased IL-1 $\beta$ level (7).

Regular physical activity or exercise serves as one of the most consistently effective tools for children's healthy lifestyle since exercise positively affects their self-image, motor development, psychosocial and behavioral complications (10). A number of studies suggest physical exercise-based treatment to improve markers of inflammation in healthy and diseased people. After participating in physical activity programs, Goldhammer et al. and Forti et al. found a significant decrease in IL-1 $\beta$ and a significant increase in IL-1RA levels, respectively $(11,12)$. On the other hand, Moon et al. and Mendham et al. observed no improvement in IL$1 \beta$ and IL-1RA levels $(13,14)$.

In addition, many studies evaluated the effect of various types of exercises for the improvement of stereotypic behaviors in ASD children and demonstrated that physical activity could be an effective and fun approach for this population $(10,15,16)$.

Inadequate vitamin D status is prevalent in the ASD population (17). Biological studies indicate that vitamin $\mathrm{D}$ is a fundamental modulator of immune function and inflammation. The active form of $25(\mathrm{OH}) \mathrm{D}$, $1,25(\mathrm{OH}) 2$ has an anti-inflammatory impact on the inflammatory profile of monocytes and can downregulate the expression and production of different proinflammatory cytokines, including TNF- $\alpha$, IL-1 $\beta$, IL-6, and IL-8 (18). 
In recent years, several studies have investigated the potential roles of vitamin $\mathrm{D}$ supplementation on the immune system, particularly on decreased inflammatory biomarkers. Razzaghi et al. and Tabesh et al. investigated the effect of vitamin D supplementation on serum inflammatory markers in diabetic adults. They observed the beneficial effects of vitamin D supplementation on levels of inflammatory biomarkers among patients with diabetes $(19,20)$. But, another study suggested that supplementary treatment did not significantly change the serum level of high-sensitive Creactive protein, IL-6, IL-8, and IL-10 (21). In addition to this, recent studies have examined the influence of vitamin D3 supplementation on the major symptoms of ASD. Previous research supported the role of vitamin D supplementation in ASD (22); however, another study reported that supplementation was not beneficial for the core symptoms of ASD (23).

Preceding studies have solely evaluated the effects of vitamin D supplementation or aquatic exercise on inflammatory biomarkers in older adults and patients with some chronic diseases, and have found inconsistent results. However, no research has been done about the effect of vitamin D supplementation or/and aquatic exercise program on inflammatory cytokines in children with ASD. Therefore, the aim of this study was to compare the effect of three interventional approaches of aquatic exercise training, vitamin D supplementation, and aquatic exercise + vitamin D supplementation on improving inflammatory cytokines, including IL-1 $\beta$ and IL-1RA and stereotypic behaviors in children with ASD.

\section{Materials and Methods}

\section{Participants:}

Forty-six children with ASD were recruited who were members of Guilan Autism Society Institute (North of Iran) and received the same treatment strategies in 2018. Inclusion criteria included: (1) psychiatrist -diagnosed ASD (by Diagnostic and Statistical Manual of Mental Disorders-Fifth Edition (DSM-V)), (2) male gender, (3) age 6-14 years, (4) no change in any medical, dietary, or behavioral treatment during the study, and (5) parental informed consent. Exclusion criteria included having a comorbid disability or other neuro-cognitive disorders, receiving vitamin D supplements in the last 6 months and absence for more than two sessions in the aquatic program.

\section{Design:}

This study was a semi-experimental research with pre and post-test, randomized controlled trial in which forty boys were recruited and randomly divided and matched into 4 groups based on age and severity of autism: aquatic $(n=10)$, supplementary $(n=10)$, aquatic + supplementation $(\mathrm{n}=10)$, and control $(\mathrm{n}=10)$ groups. An experienced physician conducted the screening of participants to determine eligibility to engage in aquatic exercise training. The control group was asked to maintain their habitual activity and dietary patterns during the study and not to take part in new programs. Participants' anthropometric features such as weight, standing height, and Body mass index (BMI) (weight $(\mathrm{kg}) /$ height $(\mathrm{m} 2)$ ) were measured in a standardized method while participants wore light clothes and no shoes for this part of the experiment. Research Ethics Committee approved the experimental protocol. All children completed the trial in full.

Five qualified and certified swimming trainers who had previous experience in teaching swimming to children with special needs, including autism, were instructed with the schedule of training techniques. In addition, a 1:2 trainer-to-child ratio was provided to ensure safety and optimal participation. All parents were asked to attend training sessions and when a child did not follow the rules or expectations, they could help and participate in the intervention program. All training 
sessions were held in the Arsen swimming pool in Rasht city from 15 to $16 \mathrm{pm}$ on Sundays and Thursdays.

\section{Interventions:}

In this study, the aquatic program was a group intervention. Each training session lasted 60 minutes, including a 5-minute warm-up, 15-minute orientation training, 20-minute basic swimming skills, 15-minute free swim and a 5-minute cool down with the temperature of the pool water maintained at $29^{\circ} \mathrm{C}$. Table 1 shows the aquatic exercise program protocol.

Table 1. Aquatic exercise program protocol

\begin{tabular}{|c|c|c|c|}
\hline Program activity & $\begin{array}{l}\text { Length } \\
\text { (min) }\end{array}$ & content & goal \\
\hline warm-up & 5 & $\begin{array}{l}\text { walking clockwise and counterclockwise, running in } \\
\text { place, jumping jacks, blowing bubbles and reciprocal arm } \\
\text { and leg movements }\end{array}$ & $\begin{array}{l}\text { Warm-up and Water } \\
\text { adjustment }\end{array}$ \\
\hline $\begin{array}{l}\text { orientation } \\
\text { training }\end{array}$ & 15 & Sagittal, transversal, and longitudinal rotation & Water orientation \\
\hline $\begin{array}{l}\text { basic swimming } \\
\text { skills }\end{array}$ & 20 & Breathing, Floating, and Stroke skills & swimming skills \\
\hline free swim & 15 & $\begin{array}{l}\text { Group activities: Ball toss and catch, cross through hula- } \\
\text { hoop, red light/green light, allowed to play pool toys, } \\
\text { noodles, and kickboards }\end{array}$ & $\begin{array}{l}\text { Communication and } \\
\text { Social interaction }\end{array}$ \\
\hline cool down & 5 & The same as warm-up & \\
\hline
\end{tabular}

The serum 25(OH) D levels were measured by highperformance liquid chromatography. Deficiency and insufficient levels of vitamin D were differently defined in some studies, but in the present research normal, inadequate, and deficient vitamin D3 levels were considered to be above $30 \mathrm{ng} / \mathrm{ml}$, between 20 to 30 $\mathrm{ng} / \mathrm{mL}$, and below $20 \mathrm{ng} / \mathrm{ml}$, respectively (24). In this research, it is necessary to mention that all children had inadequate and deficient levels of vitamin D and were advised to receive vitamin D3 supplementation.

A therapeutic dose of vitamin D3 was prescribed by a specialist physician so that participants who had inadequate levels of vitamin $\mathrm{D}$ took vitamin $\mathrm{D}$ once every two weeks $(n=3)$, and those who had deficient levels of vitamin D took vitamin D once a week $(n=17)$. Vitamin D3 was orally administered at a dosage of
50,000 IU after dinner, provided by Dana Pharmaceutical Company (in total 10 weeks).

The aquatic + supplementation intervention combined the above interventions, such that on Sundays and Thursdays, participants and their parents/caregivers attended an aquatic exercise program in swimming pool from 4 to $5 \mathrm{pm}$; and received vitamin D supplementation according to the prescribed therapeutic dose.

\section{Measurements:}

The stereotype subscale of Gilliam Autism Rating Scale-Second Edition (GARS-2) (Gilliam, 2006), a 14item informant was used to figure out changes in participants' stereotype severity. GARS-2 was utilized in previous studies. Special, measurable, and observable restricted and repetitive behaviors could be characterized by the stereotype subscale. It includes observations, parent or teacher interviews, and questions 
completed by the examiner according to their interpretation. For each item, the caregiver (or parents/teachers) is asked to select 1 of 4 choices that best reveal the child's special stereotypical behavior using objective frequency-based ratings of four points (0: indicates that the behavior is never observed, and 3: indicates that the behavior is frequently observed). The items of the subscale ask caregivers how often a child: 1. Avoids eye contact/looks away; 2. Stares at hands or objects; 3. Flicks fingers rapidly; 4. Eats specific foods; 5. Licks or tastes inedible; 6. Smells/sniffs objects; 7. Whirls or turns in circles; 8. Spins objects; 9. Rocks back and forth; 10. Rapid lunging/darting; 11. Prances; 12. Flaps hands; 13. Makes high-pitched sounds; and 14. Slaps, hits, bites self. Higher scores indicate a higher level of stereotypes. According to frequency of occurrence of each stereotyped behavior under routine circumstances in a $6-\mathrm{h}$ period, caregivers reply to rate the child's behavior. In this study, the total raw score of this subscale was considered (10). Validity, reliability, and psychometric properties of the subscale were measured by previous research (25).

Five milliliters of venous blood samples were collected at the beginning and the end of the study at
Razi laboratory in a fasting status between 7 to 9 a.m. and centrifuged at $3000 \times \mathrm{g}$ for $15 \mathrm{~min}$ to separate serum. The separated serum was stored frozen at $-70^{\circ} \mathrm{C}$ until analysis. Serum IL-1 $\beta$ and IL-1RA were measured by human ELISA kit (Diaclone; France and Zellbio; Germany, respectively), according to the manufacturer's instructions.

\section{Statistics:}

Descriptive data, including demographic characteristics of participants, age, weight and height were reported as mean and standard deviation (As shown in Table 2). Meanwhile, statistical tests, including Shapiro-Wilk and Leven's tests were used to check the normality and homogeneity of variances of the data, respectively; and ANCOVA was utilized to investigate the research hypotheses, as the data were normally distributed. In the event of a significant $F$ ratio, Bonferroni post-hoc test was used for pairwise comparisons. The effect size was computed and reported as a $\eta 2$ value for ANCOVA evaluations. P values less than 0.05 were considered statistically significant. SPSS (Version 25.0) software was used for statistical analyses.

Table 2. Participants' demographic characteristics

\begin{tabular}{|c|c|c|c|c|c|c|c|c|c|c|c|}
\hline \multirow{3}{*}{ variables } & \multicolumn{2}{|l|}{ AG } & \multicolumn{2}{|l|}{ SG } & \multicolumn{2}{|l|}{ COG } & \multicolumn{2}{|l|}{$\mathrm{CG}$} & \multicolumn{2}{|c|}{$\begin{array}{l}\text { Statistics } \\
\text { ANCOVA }\end{array}$} & \multirow[t]{3}{*}{ Group differences } \\
\hline & \multicolumn{2}{|c|}{ Mean (SD) } & \multicolumn{2}{|c|}{ Mean (SD) } & \multicolumn{2}{|c|}{ Mean (SD) } & \multicolumn{2}{|c|}{ Mean (SD) } & \multirow{2}{*}{$\begin{array}{l}\mathrm{F} \\
(3,35)\end{array}$} & \multirow[b]{2}{*}{$\eta 2 p$} & \\
\hline & $\begin{array}{l}\text { Pre- } \\
\text { test }\end{array}$ & $\begin{array}{l}\text { Post- } \\
\text { test }\end{array}$ & $\begin{array}{l}\text { Pre- } \\
\text { test }\end{array}$ & $\begin{array}{l}\text { Post- } \\
\text { test }\end{array}$ & Pre-test & $\begin{array}{l}\text { Post- } \\
\text { test }\end{array}$ & Pre-test & $\begin{array}{l}\text { Post- } \\
\text { test }\end{array}$ & & & \\
\hline IL-1及 & $\begin{array}{l}10.90 \\
(1.79)\end{array}$ & $\begin{array}{l}9.50 \\
(1.50)\end{array}$ & $\begin{array}{l}10.70 \\
(1.76)\end{array}$ & $\begin{array}{l}10.20 \\
(2.14)\end{array}$ & $\begin{array}{l}10.30 \\
(2.21)\end{array}$ & $\begin{array}{l}7.40 \\
(1.42)\end{array}$ & $\begin{array}{l}9.55 \\
(2.19)\end{array}$ & $\begin{array}{l}9.59 \\
(2.19)\end{array}$ & $14.19^{*}$ & 0.54 & $\mathrm{COG}>\mathrm{AG}>\mathrm{SG}>\mathrm{CG}$ \\
\hline IL-1RA & $\begin{array}{l}132.6 \\
(9.51)\end{array}$ & $\begin{array}{l}124.6 \\
(8.80) \\
\end{array}$ & $\begin{array}{l}132.00 \\
(8.17)\end{array}$ & $\begin{array}{l}130.90 \\
(7.99)\end{array}$ & $\begin{array}{l}135.77 \\
(8.58) \\
\end{array}$ & $\begin{array}{l}124.40 \\
(8.32) \\
\end{array}$ & $\begin{array}{l}133.20 \\
(7.82) \\
\end{array}$ & $\begin{array}{l}131.30 \\
(5.61)\end{array}$ & $5.14 *$ & 0.30 & $\begin{array}{l}\mathrm{AG}>\mathrm{COG} \\
>\mathrm{SG}>\mathrm{CG}\end{array}$ \\
\hline S.B. & $\begin{array}{l}14.30 \\
(2.49)\end{array}$ & $\begin{array}{l}12.60 \\
(2.83)\end{array}$ & $\begin{array}{l}13.80 \\
(2.65)\end{array}$ & $\begin{array}{l}13.10 \\
(2.8)\end{array}$ & $\begin{array}{l}13.50 \\
(3.13)\end{array}$ & $\begin{array}{l}9.70 \\
(2.58)\end{array}$ & $\begin{array}{l}14 \\
(3.19)\end{array}$ & $\begin{array}{l}13.90 \\
(2.84)\end{array}$ & $29.52 *$ & 0.71 & $\mathrm{COG}>\mathrm{AG}>\mathrm{SG}>\mathrm{CG}$ \\
\hline
\end{tabular}




\section{Results}

In total, 40 ASD children were recruited for this study. Table 3 shows the demographic information for the four groups in pre-test and post-test. There was a significant difference in mean $\operatorname{IL}-1 \beta[\mathrm{F}(3,35)=14.19$, $\mathrm{p}=0.001, \eta 2 \mathrm{p}=0.54)$ ] between the groups, whilst adjusting for pre-test of IL-1 $\beta$. Post hoc tests showed that there were significant differences between Aquatic exercise and combination groups $(\mathrm{p}=0.008)$, supplementation and combination groups $(\mathrm{p}=0.001)$, and combination and control groups $(\mathrm{p}=0.001)$.

A significant difference was observed in mean IL$1 \mathrm{RA}[\mathrm{F}(3,35)=5.14, \mathrm{p}=0.005, \mathrm{\eta} 2 \mathrm{p}=0.31)]$ between the groups, whilst adjusting for pre-test of IL-1RA. Post-hoc tests showed that there were considerable differences between supplementation and combination groups $(\mathrm{p}=0.021)$ and combination and control groups $(\mathrm{p}=$ 0.026).

Furthermore, there was a significant difference in mean S.B scores $[F(3,35)=29.52, p=0.001, \eta 2 p=0.71)]$ between the groups, whilst adjusting for pre-test of S.B. Post-hoc tests addressed that there were significant differences between Aquatic exercise and control groups $(\mathrm{p}=0.005)$, Aquatic exercise and combination groups $(\mathrm{p}=0.001)$, supplementation and combination groups $(\mathrm{p}=0.001)$, and combination and control groups $(\mathrm{p}=0.001)$.

Table 3. Serum IL-1 $\beta$ and IL-1RA concentration and S.B scores in all groups

\begin{tabular}{|c|c|c|c|c|c|c|c|c|}
\hline \multicolumn{3}{|c|}{ Aquatic exercise group } & \multicolumn{2}{|c|}{ Supplementation group } & \multicolumn{2}{|c|}{ Combination group } & \multicolumn{2}{|c|}{ Control group } \\
\hline Mean & & & Mean & & Mean & & & \\
\hline \multirow[t]{2}{*}{ (SD) } & & & (SD) & & (SD) & & (SD) & \\
\hline & Pre-test & Post-test & Pre-test & Post-test & Pre-test & Post-test & Pre-test & Post-test \\
\hline \multirow[t]{2}{*}{ Age } & 10.90 & - & 10.30 & - & 9.70 & - & 10 & - \\
\hline & $(3.10)$ & & $(2.90)$ & & $(3.05)$ & & $(2.90)$ & \\
\hline \multirow[t]{2}{*}{ Height } & 1.53 & - & 1.40 & - & 1.45 & - & 1.41 & - \\
\hline & $(0.095)$ & & $(1.48)$ & & $(0.121)$ & & $(.145)$ & \\
\hline \multirow[t]{2}{*}{ Weight } & 57.90 & 53.50 & 47.10 & 45.70 & 54 & 45.80 & 46.90 & 46.90 \\
\hline & (10.19) & $(9.40)$ & $(15.72)$ & $(14.26)$ & (11.39) & $(11.47)$ & $(13.70)$ & $(13.78)$ \\
\hline \multirow[t]{2}{*}{ BMI } & 24.31 & 22.45 & 23.13 & 22.57 & 25.36 & 21.40 & 23.24 & 23.24 \\
\hline & $(1.90)$ & $(1.46)$ & $(3.42)$ & $(2.84)$ & $(1.28)$ & & $(3.70)$ & \\
\hline \multirow[t]{2}{*}{ VIT.D } & 10.32 & 9.96 & 11.12 & 31.60 & 10.70 & 31.90 & 10.30 & 10.20 \\
\hline & $(4.38)$ & (4.11) & $(4.29)$ & $(4.45)$ & (4.98) & $(4.93)$ & $(4.21)$ & $(3.88)$ \\
\hline
\end{tabular}

AG: Aquatic exercise group; SG: Supplementation group; COG: Combination group; CG: Control group $* \mathrm{p}<.05$

\section{Discussion}

To the best of our knowledge, we present one of the first studies aimed at investigating the water-based intervention and vitamin D supplementation on special inflammatory cytokines in children with ASD.
The main aim of the present research was to compare the 10-weeks efficacy of three interventional approaches, including aquatic exercise training program, vitamin D supplementation, and the combined exercise + supplementation on inflammatory response in 
ASD children. We demonstrated that aquatic exercise, vitamin D supplementation, and the combination groups could lead to a significant decrease in the IL-1 $\beta$ serum level, but IL-1RA decreased significantly in the combination group.

Many experimental studies have reported that the prevalence of vitamin D insufficiency and deficiency were common in people with ASD $(22,24)$, which may be the cause of a significant percentage of ASD. Some studies have examined the effect of vitamin D supplementation in patients with some chronic diseases such as type-2 diabetes or knee osteoarthritis $(19,20)$. Razzaghi et al. and Tabesh et al. found that following supplementation with vitamin D3, significant reductions were observed in inflammatory biomarkers. In contrast, another research revealed that long-term vitamin D supplementation had no beneficial effect on inflammatory serum levels (21). However, no study has investigated the effect of vitamin D supplementation on inflammatory biomarkers in ASD population. For the first time, the results of this study revealed that vitamin D supplementation alone, and in combination with aquatic activity could significantly decrease the serum levels of two pro-inflammatory (IL-1 $\beta$ ) and antiinflammatory (IL-1RA) markers, respectively.

In recent years, there has been an attempt to discover the possible roles of vitamin D on the immune system, specifically on $\mathrm{T}$ cell-mediated immunity and inflammation. Vitamin D, a group of fatsoluble secosteroids, may have anti-inflammatory effects, as it stimulates phagocytosis, destroys the bacteria by macrophages, suppresses interferon-gmediated macrophage activation, and downregulates cytokine generation (26).

The findings of the current study, also demonstrated that aquatic exercise training alone, and in combination with supplementation led to significant reductions in IL$1 \beta$ and IL-1RA, respectively. Interestingly, the decrease in IL-1 $\beta$ and IL-1RA serum level was higher in the combination group than in the other groups. In line with this finding, Chin et al. investigated the relationship between regular physical activity and vitamin D sufficiency, and their joint role in healthy living. They found that the two factors working together seemed to somehow do more than either factor alone to protect the cardiovascular system (27).

Higher inflammatory cytokines, including IL- $1 \beta$ and IL-1RA, have been associated with $\operatorname{ASD}(4,7,9)$. IL$1 \beta$ is an essential mediator of inflammatory responses, including cell proliferation, differentiation, and apoptosis. It is not surprising that this cytokine can serve as a marker for abnormal response in subjects with ASD. On the other hand, IL-1RA binds to the cell surface IL1 receptor, inhibits the activities of IL-1 $\beta$, and modulates IL-1-related immune responses (7).

To the best of our knowledge, no study has investigated the impact of any type of exercise on inflammatory biomarkers, especially IL-1 $\beta$ and IL-1RA in ASD population. Regarding the effect of physical activity on inflammation, previous studies used various forms of exercise, including aerobic training in coronary heart disease patients (12), resistance training in young adults (11), mental exercise in people with Parkinson's Disease (14), and cycling in sedentary, middle-aged men (13), and they reported inconsistent results.

It has been explored that regular exercise may suppress chronic low-grade inflammation profile (CLIP) and could serve as a safe and cost-effective approach to improve CLIP (11). Current data show that immunosenescence may be ameliorated by usual physical activity and suppress systemic inflammation $(28,29)$. Studies found that skeletal muscle contraction is the main origin of exercise-induced cytokinestermed myokines — which mediate the exercise-induced beneficial effects (30). The precise mechanism explaining the exercise-induced immunomodulation is 
not yet completely understood, but the antiinflammatory effect of regular exercise stands out as one of the key mechanisms (11).

Another objective of this research was to compare the effects of the three interventional approaches on stereotypic behaviors in children with ASD. The results showed that all three interventions significantly decreased S.B scores in ASD participants. Our findings are in line with studies evaluating the effect of martial arts (10), walking and running (15), and aquatic exercise $(16,31)$ on behavior problems in ASD children.

There are several reasons why exercise can help reduce stereotyped behaviors in people with autism. Exercise is a fun recreational activity that does not require cognition, and therefore can be less stressful for children. Disappointment caused by failure is also eliminated and children can participate in activities that can lead to success. The other positive effect, an important aspect of exercise for autistic children, is freedom. Organizational principles such as low studentto-teacher ratios, structured environments, and routines are essential for this training and they should be considered before actual training. Furthermore, aquatic exercise puts less stress on the joints than other sports (31).

On the other hand, previous studies demonstrated that vitamin $\mathrm{D}$ was incorporated in numerous brain bioprocesses including neurotrophism, neuroimmunodulation, and neurotransmission and played a crucial role in brain functions. Therefore, the core clinical symptoms of ASD could reduce through vitamin D supplementation. Antioxidant, brain protection, immune modulation, modifying the genetic mutation, and elevating brain serotonin content are several underlying mechanisms of maintaining sufficient vitamin D serum level in children with ASD (32). Also, vitamin D supplementation along with aquatic exercise as a safe and non-expensive intervention may probably induce the best results to improve ASD problems.

There have been some limitations in the current study. First, the number of samples was small because parents and caregivers were not willing to let their children participate in the blood process twice. Second, there is a need for a follow-up evaluation to judge the stability of these effects over time. Third, there has not been a placebo group to compare the results of supplementary and placebo groups. Finally, the medication was used by some of the participants in the study included Risperidone, Aripiprazole, Ritalin, and Omega-3, but the researcher did not control their effects.

\section{Conclusions}

Our results provide support for aquatic exercise and vitamin D supplementation, as important, safe, and inexpensive options for children with ASD to improve inflammatory serum levels and stereotypic behaviors. However, the decrease in S.B, IL-1 $\beta$, and IL-1RA serum level was higher in the combination group than in the other groups.

\section{Conflict of interest}

The authors declare no competing financial interests.

\section{Acknowledgments}

The authors would like to thank all of the children and parents who participated in this study. We would also like to thank the Guilan Autism Society Institute staff for their help and support for this study; and finally, we thank trainers and lifeguards, particularly $\mathrm{Mr}$. Tirafkan.

\section{References}

1. Estes M L, McAllister A K. Immune mediators in the brain and peripheral tissues in autism spectrum disorder. Nat Rev Neurosci 2015 ;16(8): 469-86. 
2. Mohammadi M R, Ahmadi N, Khaleghi A, Zarafshan H, Mostafavi S A, Kamali K., et al. Prevalence of Autism and its Comorbidities and the Relationship with Maternal Psychopathology: A National PopulationBased Study. Arch Iran Med 2019; 22(10): 546-53.

3. Mead J, Ashwood P. Evidence supporting an altered immune response in ASD. Immunol Lett 2015; 163(1): 49-55.

4. Ashwood P, Krakowiak P, Hertz-Picciotto I, Hansen R, Pessah I, Van de Water J. Elevated plasma cytokines in autism spectrum disorders provide evidence of immune dysfunction and are associated with impaired behavioral outcome. Brain Behav Immun 2011; 25(1): 40-5.

5. Heuer L S, Croen L A, Jones K L, Yoshida C K, Hansen R L, Yolken R, et al. An exploratory examination of neonatal cytokines and chemokines as predictors of autism risk: The Early Markers for Autism study. Biol Psychiatry 2019; 86(4): 255-64.

6. Deverman B E, Patterson P H. Cytokines and CNS development. Neuron 2009; 64(1): 61-78.

7. Suzuki K, Matsuzaki H, Iwata K, Kameno Y, Shimmura C, Kawai S. Plasma cytokine profiles in subjects with high-functioning autism spectrum disorders. PloS one 2011; 6(5): e20470.

8. Goines P E, Ashwood P. Cytokine dysregulation in autism spectrum disorders (ASD): possible role of the environment. Neurotoxicol Teratol 2013; 36: 67-81.

9. Ansari Kolachahi S, Hojjati Zidashti Z, Elmieh A, Bidabadi E, Filli J. The relationship between the cytokines and hs-CRP levels in children with autism and their comparison with healthy ones. Medical Sciences 2019; 29(3): 240-48.

10. Bahrami F, Movahedi A, Marandi S M, Abedi A. Kata techniques training consistently decreases stereotypy in children with autism spectrum disorder. Res Dev Disabil 2012, 33(4), 1183-93.

11. Forti LN, Van Roie E, Njemini R, Coudyzer W, Beyer I, Delecluse C, Bautmans I. Effects of resistance training at different loads on inflammatory markers in young adults. Eur J Appl Physiol 2017; 117(3): 511-9.
12. Goldhammer E, Tanchilevitch A, Maor I, Beniamini Y, Rosenschein U, Sagiv M. Exercise training modulates cytokines activity in coronary heart disease patients. Int J Cardiol 2005; 100(1): 93-9.

13. Mendham A E, Duffield R, Marino F, Coutts AJ. Small-sided games training reduces CRP, IL-6 and leptin in sedentary, middle-aged men. Eur J Appl Physiol 2014; 114(11): 2289-97.

14. Moon S, Schmidt M, Smirnova I V, Colgrove Y, Liu W. Qigong exercise may reduce serum TNF- $\alpha$ levels and improve sleep in people with Parkinson's disease: A pilot study. Medicines 2017; 4(2): 23.

15. Celiberti D A, Bobo HE, Kelly KS, Harris SL, Handleman JS. The differential and temporal effects of antecedent exercise on the self-stimulatory behavior of a child with autism. Res Dev Disabil 1997; 18(2): 139-50.

16. Adib Saber F, Shojaei M, Daneshfar A, Hossein Khanzadeh A. Aquatic Exercise on Stereotypic Behaviors and Sleep Habits in Children with Autism Spectrum Disorder. Middle Eastern Journal of Disability Studies 2019; 9: 110.

17. Wang T, Shan L, Du L, Feng J, Xu Z, Staal WG, et al. Serum concentration of 25-hydroxyvitamin D in autism spectrum disorder: a systematic review and metaanalysis. Eur Child Adolesc Psychiatry 2016; 25(4): 341-50.

18. Neve A, Corrado A, Cantatore FP. Immunomodulatory effects of vitamin $\mathrm{D}$ in peripheral blood monocytederived macrophages from patients with rheumatoid arthritis. Clin Exp Med 2014; 14(3): 275-83.

19. Razzaghi R, Pourbagheri H, Momen-Heravi M, Bahmani F, Shadi J, Soleimani Z, et al. The effects of vitamin D supplementation on wound healing and metabolic status in patients with diabetic foot ulcer: a randomized, double-blind, placebo-controlled trial. J Diabetes Complications 2017; 31(4): 766-72.

20. Tabesh M, Azadbakht L, Faghihimani E, Tabesh M, Esmaillzadeh A. Calcium-vitamin D cosupplementation influences circulating inflammatory biomarkers and adipocytokines in vitamin D-insufficient diabetics: a 
randomized controlled clinical trial. J Clin Endocrinol Metab 2014;99(12):E2485-93.

21. Zheng S, Wang B, Han W, Zhu Z, Wang X, Jin X, et al. Vitamin D supplementation and inflammatory and metabolic biomarkers in patients with knee osteoarthritis: post hoc analysis of a randomised controlled trial. Br J Nutr 2018; 120(1): 41-8.

22. Feng J, Shan L, Du L, Wang B, Li H, Wang W, et al. Clinical improvement following vitamin D3 supplementation in autism spectrum disorder. Nutr Neurosci 2017; 20(5): 284-90.

23. Kerley CP, Power C, Gallagher L, Coghlan D. Lack of effect of vitamin D3 supplementation in autism: a 20week, placebo-controlled RCT. Arch Dis Child 2017; 102(11): 1030-6.

24. Mostafa G A, Al-Ayadhi LY. Reduced serum concentrations of 25-hydroxy vitamin D in children with autism: relation to autoimmunity. J Neuroinflammation 2012; 9(1): 201.

25. Worley JA, Matson JL. Diagnostic instruments for the core features of ASD. In International handbook of autism and pervasive developmental disorders (pp. 215231). New York, NY: Springer; 2011.

26. Van Etten E, Decallonne B, Bouillon R, Mathieu C. NOD bone marrow-derived dendritic cells are modulated by analogs of 1, 25-dihydroxyvitamin D3. J Steroid Biochem Mol Biol 2004; 89: 457-9.

27. Chin K, Zhao D, Tibuakuu M, Martin S S, Ndumele CE, Florido R, et al. Physical activity, vitamin D, and incident atherosclerotic cardiovascular disease in whites and blacks: the ARIC study. J Clin Endocrinol Metab 2017; 102(4): 1227-36.

28. Gleeson M, Bishop NC, Stensel DJ, Lindley MR, Mastana SS, Nimmo M A. The anti-inflammatory effects of exercise: mechanisms and implications for the prevention and treatment of disease. Nat Rev Immunol 2011;11(9): 607-15.

29. Petersen A M W, Pedersen B K. The anti-inflammatory effect of exercise. J Appl Physiol 2005; 98(4): 1154-62.

30. Wagenmakers AJ, Pedersen BK. The anti-inflammatory effect of exercise: its role in diabetes and cardiovascular disease control. Essays Biochem 2006;42:105-17.

31. Vonder Hulls D S, Walker LK, Powell J M. Clinicians' perceptions of the benefits of aquatic therapy for young children with autism: A preliminary study. Phys Occup Ther Pediatr 2006; 26(1-2): 13-22.

32. Jia F, Shan L, Wang B, Li H, Feng J, Xu Z, et al. Fluctuations in clinical symptoms with changes in serum $25(\mathrm{OH})$ vitamin D levels in autistic children: three cases report. Nutr Neurosci 2019; 22(12): 863-6. 